\title{
Indagació basada en la modelització: un marc per al treball pràctic
}

\author{
Cristina Simarro Rodríguez (cristina.simarro.rodriguez@uab.cat) \\ Digna Couso Lagarón (digna.couso@uab.cat) \\ Roser Pintó Casulleras (roser.pinto@uab.cat) \\ Centre de Recerca per a l'Educació Científica i Matemàtica (CRECIM). Universitat Autònoma de Barcelona.
}

Malgrat la rellevància que la recerca en didàctica de les ciències sembla donar a l'ensenyament de les ciències basat en la indagació, molts autors afirmen que aquest tipus de pràctica educativa no ha arribat a uns nivells de qualitat acceptable en la seva implementació a l'aula. La gran varietat d'interpretacions que se li dóna al terme indagació $i$ la desconnexió d'aquestes amb altres aspectes rellevants de la didàctica de les ciències com la modelització són algunes de les causes que explicarien aquest fet. El present article pretén introduir un marc específic per a la indagació, el de la indagació basada en la modelització, per tal d'orientar el treball pràctic a l'aula de ciències.

Paraules clau: Ensenyament de les Ciències Basat en la Indagació, Indagació Basada en la Modelització, Treball pràctic

Despite the importance that research in science education seems to give to inquiry-based science education, many authors claim that this type of educational practice has not reached acceptable levels of quality in its classroom implementation. The variety of interpretations given to the term inquiry and their disconnetion with other relevant aspects of science education such as modeling are some of the reasons that explain this situation. This article aims to introduce a specific framework for inquiry, the inquiry-based modeling to guide the practical work in the science classroom.

Key words: Inquiry-Based Science Education, Model-Based Inquiry, Practical Work

\section{INTRODUCCIÓ}

Des de fa moltes dècades, l'ensenyament de les ciències basat en la indagació $(\mathrm{ECBl})^{1}$ ha guanyat protagonisme en l'ensenyament de les ciències (Rocard et al. 2007, Osborne \& Dillon 2008). El suposat "èxit acual" (Léna 2009) de tal mètode sembla invitar a difondre'l (Viennot, 2011). Alguns autors afirmen que involucrar a l'alumnat en una indagació científica pot aportar diversos beneficis com augmentar la seva motivació, ajudar al desenvolupament de ciutadans autònoms amb pensa-

\footnotetext{
${ }^{1}$ ECBI, Ensenyament de les Ciències Basat en la Indagació ; IBSE per les seves sigles en anglès (Inquiry-Based Science Education)
}

ment crític i independent i preparar a futurs científics (Demir \& Abell, 2010). Per tant, tot i que no és l'única estratègia a utilitzar i que hi ha bastant consens sobre el fet que no tots els conceptes científics poden o han de ser ensenyats mitjançant la indagació (NRC, 1996), podríem afirmar que aquesta pot tenir un paper important per l'ensenyament de les ciències (Barrow, 2006).

Malgrat les potencialitats apuntades, molts estudis han evidenciat que aquest tipus de pràctica educativa no ha arribat a uns nivells de qualitat acceptable en la seva implementació a l'aula. En aquest sentit la recerca educativa està tendint a centrar-se cada vegada més en la comprensió de la dinàmica de l'ensenyament a través de la inda- 
gació i en com poder portar-la a terme a l'aula (Anderson, 2002). Entre d'altres motius, aquestes mancances semblen radicar en el fet que diferents autors han donat definicions ben diverses sobre allò que suposa la indagació com a aproximació didàctica, fet que porta a etiquetar com a indagació certs dissenys didàctics que no tothom veuria com a tal i que provoca, indefectiblement, una confusió entre el professorat.

\section{ENSENYAMENT DE LES CIENCIES BASAT EN LA INDAGACIÓ: VISIONS I CRITIQUES}

Com comentaven en la introducció, la interpretació que es fa del concepte d'indagació és variada i poc clara. Per exemple, en països on la indagació es una estratègia dirigida i privilegiada curricularment (com per exemple als Estats Units amb els Standards (NRC, 1996, 2000a) es troba en la recerca i també entre el professorat obligat a implementarla, una visió molt parcial sobre la indagació, en la qual s'entén com a indagació únicament aquelles activitats originades pel propi alumnat, que requereixen la seva participació a nivell pràctic i que estan totalment centrades en el mateix alumnat (Abdulkadir Demir \& Abell, 2010). Aquest marc tan rígid pot portar a frustració per part d'aquells que han de dur a l'aula la indagació, doncs dóna poc marge a la gran varietat de situacions que ens podem trobar a classe. Una altre problema important serien les visions d'indagació de tipus merament tècnic-manipulatiu (hands-on) enfront de visions molt més discursiu-cognitives (més orientades al minds-on) (Garrido \& Couso, 2013). Projectes i iniciatives de gran ressò com ara La main à la pâte o Pollen, així com algunes de les directrius de l'informe Rocard (2007) semblen privilegiar la primera visió respecte la segona, sobretot a l'aula de primària, entenent la indagació com un enfocament didàctic centrat en fomentar que l'alumnat faci de científic però no en que pensi com a tal. És a dir, manquen d'un enfocament didàctic per fer que l'activitat de l'aula de ciències sigui de pràctica científica el més autèntica possible.

Amb l'objectiu d'esvair la confusió que existeix al voltant del concepte d'indagació, una revisió de les postures més citades en la literatura ens permetria destacar tres dimensions a l'hora de parlar d'indagació (Barrow, 2006):

a) aquelles capacitats cognitives que els estudiants haurien de desenvolupar, b) allò que cal que l'alumnat entengui sobre els mètodes utilitzats pels científics per tal de donar resposta a les seves preguntes $i$

c) una varietat d'estratègies que el professorat ha de desenvolupar per tal que l'alumnat aprengui capacitats d'indagació (a) i sobre la indagació científica (b) , així com per comprendre i aprendre conceptes científics.

Per tant, mentre a i b fan referència a continguts per fer ciències o sobre ciències que s'espera que l'alumnat aprengui, la tercera dimensió es refereix a un enfocament didàctic que permet treballar tant aquests continguts com els continguts de ciències (Hodson, 1992). La Figura 1 resumeix aquestes tres dimensions a les quals trobem referida la indagació.

\begin{tabular}{|c|c|c|c|}
\hline \multirow[t]{2}{*}{$\begin{array}{l}\text { INDAGACIÓ } \\
\text { entesa com a: }\end{array}$} & & $\begin{array}{l}\text { Aprenentatge de capacitats cognitives i } \\
\text { tècniques que els estudiants haurien } \\
\text { de desenvolupar } \\
\text { Aprenentatge d'allò que cal que } \\
\text { l'alumnat entengui sobre els mètodes } \\
\text { utilitzats pels científics per al de donar } \\
\text { resposta a les seves preguntes }\end{array}$ & $\begin{array}{l}\text { Indagació com } \\
\text { a contingut } \\
\text { (per fer ciències i } \\
\text { sobre ciències) }\end{array}$ \\
\hline & & $\begin{array}{l}\text { Varietat d'estratègies que el } \\
\text { professorat ha de desenvolupar per tal } \\
\text { que l'alumnat aprengui capacitats } \\
\text { d'indagació (a) i sobre la indagació } \\
\text { científica (b), així com per comprendre } \\
\text { i aprendre conceptes científics }\end{array}$ & $\begin{array}{c}\begin{array}{c}\text { Indagació com a } \\
\text { aproximació didàctica } \\
\text { per aprendre continguts }\end{array} \\
\text { (de i sobre ciències) }\end{array}$ \\
\hline
\end{tabular}

Figura 1. Esquema de les tres dimensions que representa el concepte d'indagació en l'ensenyament de les ciències segons la literatura

Centrant-nos en la indagació com a enfocament didactic, la National Reserach Council, d'Estats Units, la definia en els National Science Education Standards (NRC, 1996) destacant-ne cinc característiques essencials que configuren el que podríem anomenar cicle d'indagació: 1) plantejament de preguntes orientades des de la ciència que permetin la participació activa de l'alumnat, 2) recopilació de proves per part de l'alumnat per tal de permetre el desenvolupament i avaluació de les pròpies explicacions a les preguntes plantejades, 3) desenvolupament d'explicacions a partir de les pròpies proves per tal de donar respostes a les preguntes plantejades, 4) avaluació de les pròpies explicacions, que poden incloure explicacions alternatives que reflecteixin un comprensió científica i 5) comunicació i justificació de les explicacions proposades. A partir del que descriu Bybee (Bybee, 2006) aquestes cinc característiques essencials de la indagació comporten, per a l'alumnat, un seguit de tasques a nivell pràctic (hands-on) però també 
mental (minds-on) que configuren el que anomenarem cicle d'indagació i que serà el que s'adoptarà i sobre el que es discutirà en aquest article. Cal matisar, seguint al mateix autor, que amb l'objectiu de facilitar la seva transferència a l'aula aquest cicle es planteja en un continu que va des d'una indagació més guiada o pautada pel professorat fins a un protagonisme centrat essencialment en l'alumnat (Figura 2)

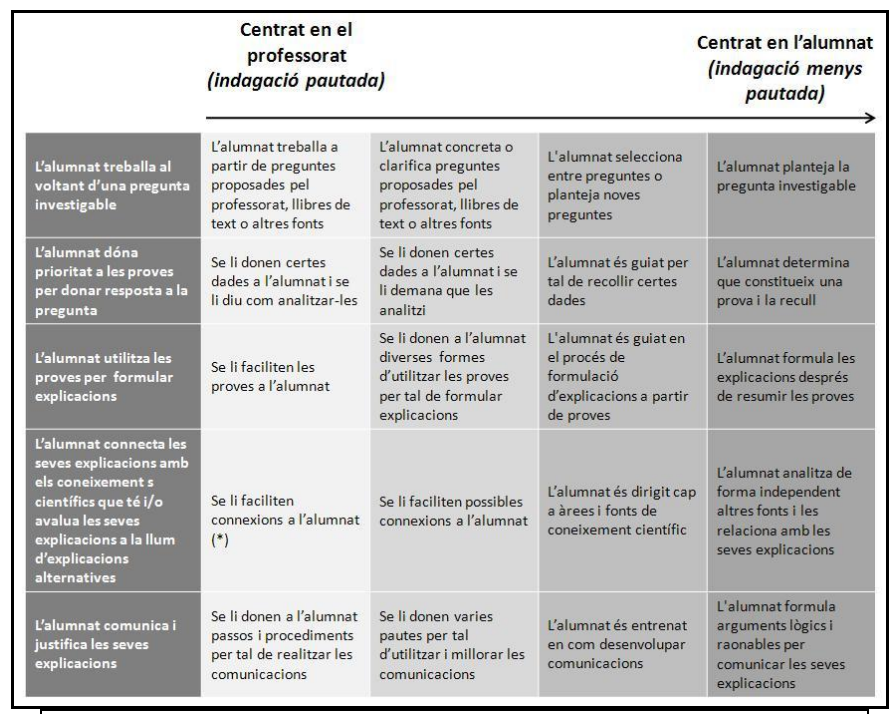

Figura 2. Possibles rols del professorat en un plantejament indagatiu (indagació més o menys pautada)

Tornant a la falta de consens respecte al significat d'indagació en el camp de l'ensenyament de les ciències, aquesta ha donat lloc a moltes veus crítiques quant a la indagació com a metodologia. D'una banda, certs autors alerten de la manca de rigor a l'hora d'analitzar l'aprenentatge real per part de l'alumnat i consideren que, sovint, els beneficis reportats s'han quedat en mesurar el grau d'entusiasme dels i les alumnes, oblidant la significativitat dels aprenentatges assolits per part de l'alumnat. És el cas de l'article de Viennot (Viennot, 2011) que defensa la necessitat de desenvolupar un component més conceptual de l'ECBI que ha de garantir una comprensió dels conceptes científics per part de l'alumnat i, encara més, l'assoliment per part del mateix d'un grau de satisfacció intel-lectual. L'autora considera que seria necessari que I'ECBI tingués un enfocament destinat a sistematitzar i organitzar els conceptes científics (una vessant més teòrica o vinculada amb la teoria).

Des d'un enfocament de l'ensenyament de les ciències modelitzador, aquesta organització dels conceptes científics implica vincular l'activitat inda- gativa amb la de modelització o construcció de models (Windschitl, Thompson, \& Braaten, 2008), entenent aquests com a aquelles representacions construïdes a partir de convenis per tal de donar suport a una activitat disciplinar o, de manera més senzilla, estructures de raonament que permeten a algú generar prediccions i explicacions (Schwarz \& Gwekwerere, 2007). En aquest sentit, en funció de com s'entengui, la indagació pot concloure amb unes explicacions locals de l'alumnat que no tinguin connexió amb la teoria científica que es vol ensenyar i aprendre. Sobre aquests problemes trobem certs autors que identifiquen pràctiques indagatives incomplertes, és a dir, sense una reflexió darrera que connecti el que es farà amb conceptes, principis, lleis o models científics. (Windschitl, Thompson, \& Braaten, 2008). Això porta en un darrer terme a unes explicacions superficials i locals, que donen resposta a una situació en concret però no van més enllà, donant una visió limitada de les ciències.

\begin{tabular}{|l|l|}
\hline & $\begin{array}{l}\text { Alguns autors afirmen que involucrar a } \\
\text { l'alumnat en una indagació científica pot } \\
\text { aportar diversos beneficis com: } \\
\text { BENEFICIS }\end{array}$ \\
POTENCIALS & $\begin{array}{l}\text { augmentar la seva motivació, } \\
\text { DE L'ECBI } \\
\text { dandar al desenvolupament de ciuta- } \\
\text { i independent, } \\
\text { aportar un coneixement més profund i } \\
\text { ric del que significa la ciència ( contin- } \\
\text { guts i processos), i } \\
\text { preparar a futurs científics }\end{array}$ \\
\hline CRÍTIQUES A & $\begin{array}{l}\text { Molts estudis han evidenciat que aquest ti- } \\
\text { pus de pràctica educativa no ha arribat a } \\
\text { uns nivells de qualitat acceptable en la seva } \\
\text { implementació a l'aula, entre d'altres per- } \\
\text { què: } \\
\text { existeix una manca de consens gene- } \\
\text { ral en el camp de la recerca sobre què } \\
\text { ha de ser considerat un enfocament } \\
\text { basat en la indagació: confusió }\end{array}$ \\
METODOLOGIA & $\begin{array}{l}\text { l'ECBI sol mancar d'un enfocament } \\
\text { destinat a aprofundir, sistematitzar i } \\
\text { organitzar els conceptes científics (no } \\
\text { buscar només la motivació de l'alumnat } \\
\text { o aspectes procedimentals) } \\
\text { falta de reflexió per connectar amb } \\
\text { conceptes, principis, lleis o models ci- } \\
\text { entífics }\end{array}$ \\
\hline
\end{tabular}

Taula 1. Resum de les potencialitats i crítiques principals a l'Ensenyament de les Ciències (ECBI) com a estratègia didàctica a l'aula de ciències

Veiem alguns exemples. El primer, recollit als National Science Education Standards (NRC, 1996, 2000b) i destacat en ells pel seu clar enfocament indagatiu i pel fet de partir d'una pregunta plantejada per l'alumnat (per tant, molt centrada en ell), consisteix en la tasca portada a terme per l'alumnat 
per donar resposta a la següent pregunta: Per què els tres arbres que hi ha al pati són ara diferents, si abans eren iguals? L'alumnat es va fer aquesta pregunta en veure que els tres arbres, que estaven un al costat de l'altre, es trobaven en estats molt diferents: un havia perdut totes les fulles, l'altre n'havia perdut una part i el tercer estava perfecte (Figura 3).

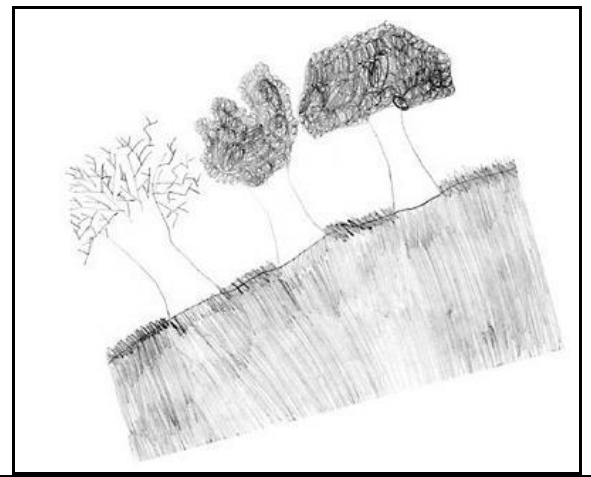

Figura 3. Per què els tres arbres que hi ha al pati són ara diferents, si abans eren iguals?

La professora els va animar a investigar què passava, seguint les característiques d'una indagació (plantejar hipòtesis, recollir dades, donar explicacions...). Finalment, l'alumnat va redactar una carta al jardiner de l'escola, amb diverses conclusions (Figura 4).

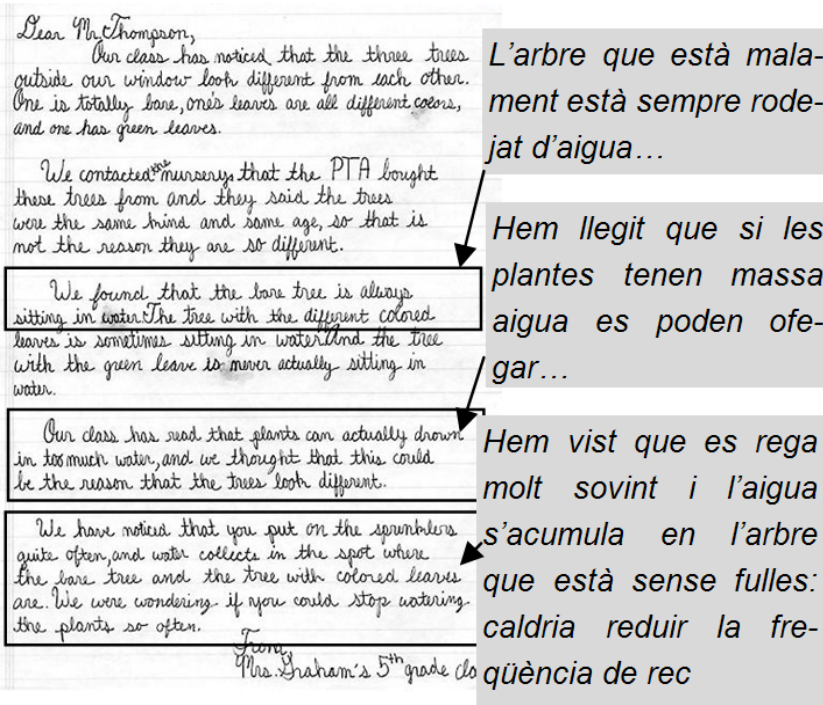

Figura 4. Conclusions de l'alumnat

Sens dubte, es tracta d'una activitat molt interessant quant al plantejament però en vista del resultat final sorgeixen varies qüestions: quin és el contingut científic que s'ha volgut treballar en aquesta activitat? L'alumnat ha arribat a construir o aplicar algun model essencial de la ciència? $O$ pel contrari s'ha quedat en una explicació local? Per exemple, es podria haver lligat la l'activitat a la construcció o aplicació del model d'èsser viu, en concret de planta, per aprofundir en la idea que si bé les plantes necessiten aigua per creixer, que hi hagi massa aigua pot donar problemes algunes plantes. D'altra banda, quina imatge de la ciència es pot estar comunicant a l'alumnat amb aquesta activitat? Es corre el risc de reduir la tasca científica queda reduïda a cercar pistes o proves, més que no pas a veure com es relacionen fenòmens $i$ teoria.

En un altre exemple, trobem una activitat en què es proposa que l'alumnat experimenti amb el fenomen per tal de descobrir què passa i què no.

"Un exemple és el de l'electrictat. Molts estudiants creuen que al posar una bombeta en un pol de la
pila és suficient per encendre-la. No hi ha res com deixar que experimentin el fenomen pel seu
compte i vegin que la bombeta no s'encendrà. Altres estudiants pensen que l'electricitat surt dels dos
pols i entra a la bombeta. D'altres especificaran que la bombeta s'encén quan l'electricitat dels dos
pols entra al mateix temps. Tot i que incorrectes, aquestes explicacions mostren una certa lógica.
L'alumnat sap que la bombeta necessita "energia" de la pila /molts tenen joguines que funcionen
amb piles) i que "l'energia" ha d'arribar a la bombeta, però no saben exactament com. Experimentar
com fer que una bombeta s'illumini amb cables il'us de més d'una bombeta en sèrie pot ajudar a
començar a ampliar les seves experiències i arribar a una conclusiódiferent."

Figura 5. Exemple d'activitat indagativa segons el projecte Pollen (Pollen, 2009, p. 16)

Seguint una estratègia de prova-error, aquesta activitat només pretén que l'alumnat porti a terme tasques tècnic-manipulatives, sense donar cap indicació sobre com abordar tasques d'ordre superior, més encaminades a donar sentit i explicació a allò que s'està fent. Sens dubte, no aprofitar l'oportunitat de portar a terme activitats pràctiques d'aquest tipus per tal de connectar-les amb la teoria, cercant d'interpretar-los des d'algun model, pot suposar una gran pèrdua de temps per al professorat i per a l'alumnat.

Davant d'aquesta situació de confusió sobre el que significa la indagació i de manca de connexió amb conceptes científics rellevants i amb una visió de ciència adient, el present article busca oferir un marc per a la indagació que supleixi algunes de les mancances destacades més amunt. En concret ho fa presentant un marc per al treball pràctic plantejat des de la indagació, donat no només que aquesta és sovint l'activitat amb què el professorat relaciona la indagació, sinó que existeixen en la recerca 
molts autors que relacionen la indagació amb el treball pràctic afirmant que aquest pot ajudar a fomentar-la (Barrow, 2006).

\section{INDAGACIÓ BASADA EN LA MODE- LITZACIÓ: UN MARC PER AL TRE- BALL PRÁCTIC}

A continuació es presenta una proposta de marc teòric d'indagació basada en la modelització per al treball pràctic, recollint algunes de les reflexions crítiques sobre la indagació i també sobre el treball pràctic, tot buscant-ne punts en comú. D'una banda una de les reflexions fonamentals fetes al voltant del treball pràctic i que ressonen amb les mancances identificades en els plantejaments indagatius, la problemàtica relació entre la teoria i la pràctica. Per a molts autors el propòsit fonamental del treball pràctic és el d'ajudar a l'alumnat a relacionar el món real dels objectes, materials i esdeveniments amb un món més abstracte com és el de les idees (Brodin, 1978; Millar et al., 1999; Shamos, 1960 citats a (Millar, 2009b). En la mateixa línea Tiberghien (Tiberghien, 2000) va caracteritzar el treball pràctic com un procés amb el que ajudar a l'alumnat a fer connexions entre el domini dels observables i el domini de les idees. Desafortunadament, els resultats d'algunes recerques posen de manifest que existeixen poques evidències sobre la consideració d'aquest propòsit per part del professorat a l'hora de dissenyar el seu treball pràctic (Millar, 2009b). D'altra banda, la falta de connexió entre el procés d'indagació i conceptes o models científics esmentada a la introducció és un altre dels aspectes considerats. En aquest sentit, la recerca que defensa una altra manera de fer la indagació, que tingui en compte una connexió constant entre fets i teoria, reclama la necessitat de focalitzar l'objectiu de la indagació en la construcció de models per part de l'alumnat.

Basant-nos en el cicle d'indagació presentat anteriorment, en les propostes d'indagació centrada en la modelització esmentades i reprenent el que s'ha recollit sobre el treball pràctic, es podria ubicar un cicle d'indagació per al treball experimental en dues dimensions: la dimensió dels objectes i la dimensió de les idees. En aquesta proposta, les fases del cicle d'indagació descrites anteriorment es reescriuen adaptant-les al treball pràctic, començant des del plantejament de preguntes a partir de l'observació d'un fenomen fins a la comprovació de les explicacions proposades, passant pel propi disseny de l'experimentació per tal de donar resposta a les preguntes (Figura 5).

Com dèiem, un treball pràctic basat en la indagació s'hauria de moure entre els dos mons esmentats. És a dir, el treball pràctic en si, que estaria al món dels observables és el context en el que promoure la reflexió i l'aprenentatge científics. D'altra banda el que hem anomenat món de les idees va més enllà de les idees de l'alumnat i es refereix a les explicacions científiques cap a on volem fer evolucionar aquestes idees, és a dir, als models que a més permeten predir o explicar noves situacions. La Figura 6 recull la proposta complerta, entenent que un treball pràctic indagatiu ha de contemplar totes les fases esmentades d'una manera més o menys pautada. Cal aclarir que per tal de poder establir les connexions entre el món real i el de les idees, la segona de les fases del cicle d'indagació (dissenyar un experiment per fer emergir proves) s'ha separat en dues $\left(n^{\circ} 2\right.$ i 3$)$, representant-se no només el procés de disseny d'un experiment sinó el procés mateix d'experimentació, incloent la recollida de dades. Com veiem, tant el plantejament de les preguntes investigables com el disseny de l'experiment es troben a la frontera entre ambdós mons. D'una banda, perquè una pregunta investigable que busqui construir un model no pot quedar-se només en el món dels observables, com tampoc ho pot fer el disseny dels experiments que ha de ser fet en funció del que sabem o volem construir d'un model científic. 


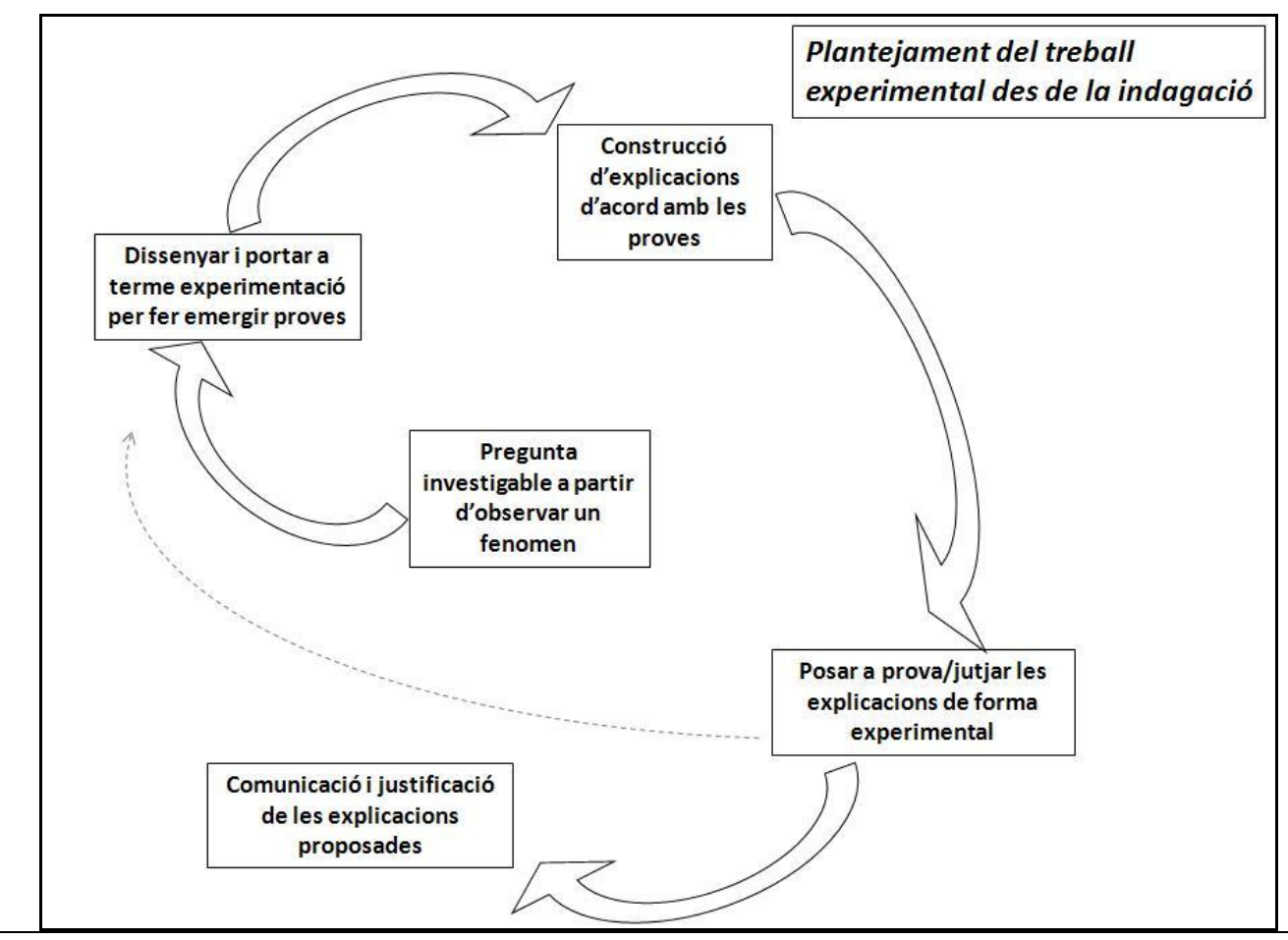

Figura 5. Proposta d'un treball experimental basat en la indagació

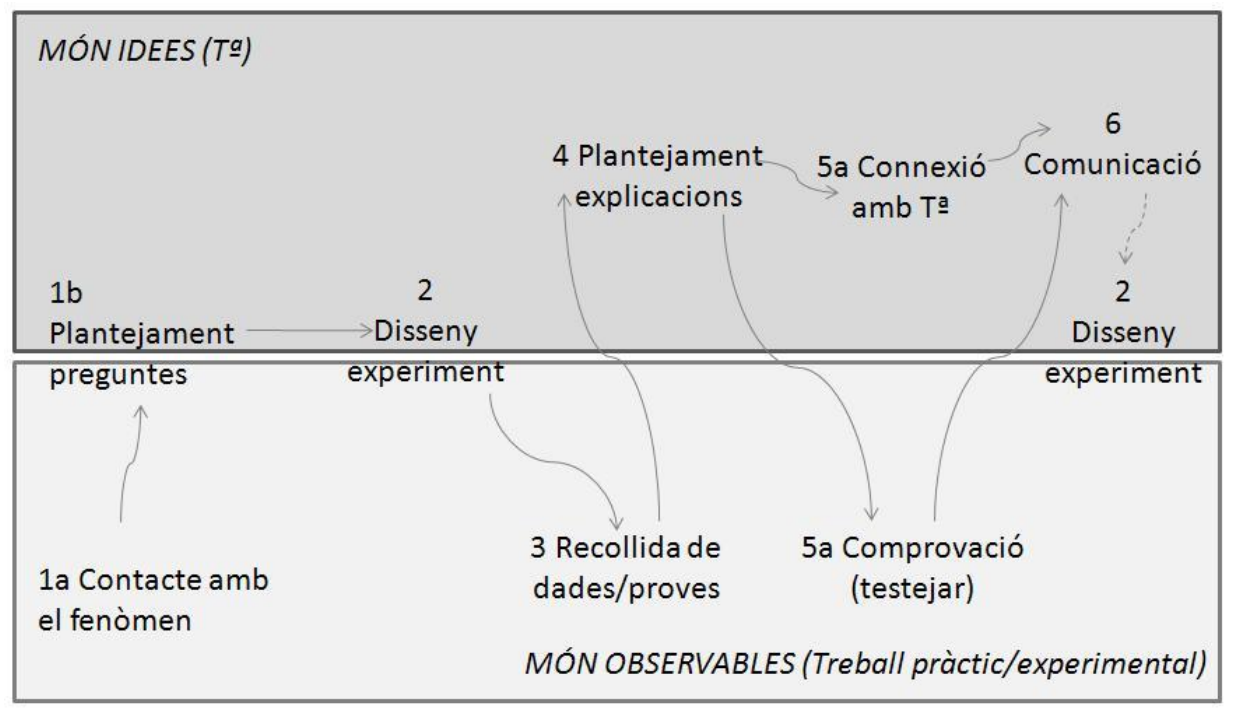

Figura 6. Proposta d'un treball experimental basat en la indagació: connexions entre el món real (dels observables) i el món de les idees

\section{APLICACIÓ DEL MARC A UN CAS CONCRET}

Amb la intenció d'exemplificar el que s'ha exposat fins al moment, a continuació es comparen dues activitats de treball pràctic enfocades a tractar el mateix concepte (el canvi químic, en concret l'oxidació). La primera de les activitats respon a un plantejament de treball pràctic que no promou la indagació.

Com podem observar en aquesta proposta de pràctica, inspirada en un format de pràctica real trobada per internet, l'alumnat disposa de totes les indicacions per a realitzar l'experiment. I no només això, sinó que no s'espera, mitjançant la realització 
de l'activitat, que l'alumnat construeixi nou coneixement, sinó simplement que comprovi un fet que ja se li exposa al principi de la pràctica (introducció teòrica). L'activitat no requereix que l'alumnat es plantegi preguntes investigables, ni dissenyi cap experiment per a donar-hi resposta. Finalment, les explicacions que es demana a l'alumnat són bastant locals, i no busquen connectar amb camp teoria ni model (en aquest cas, el canvi químic). Per exemple, es podria treballar quins són els canvis que pateix el ferro del clau (Segueix sent ferro o una cosa nova (òxid de ferro)? Com ho podríem saber? (propietats)...) per tal d'ajudar a l'alumnat a connectar amb el model que pretenem construir.

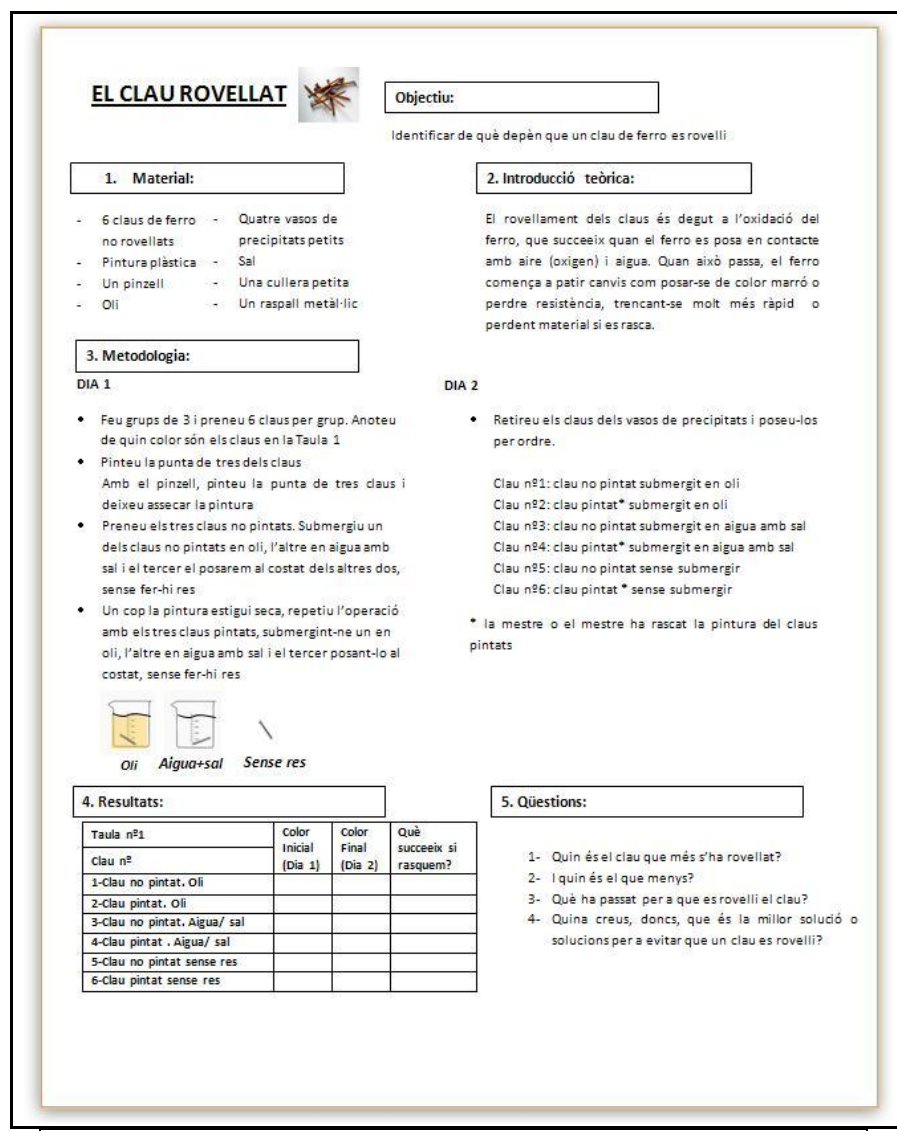

Figura 7. Treball pràctic no indagatiu

Anem a veure un exemple completament diferent. En aquest exemple es proposa a l'alumnat un exercici obert. Aquesta obertura no significa, com hem dit en fer referència a la teoria sobre indagació, que el professorat no pugui guiar a l'alumnat en tot el procés.

Veiem que aquesta activitat s'inicia plantejant una pregunta que guia la investigació i l'orienta cap al model que es vol construir. Amb preguntes com: Què miraríeu? Quins factors tindríeu en compte? $O$ Què compararíeu?, el professorat podria acompa- nya a l'alumnat en la tasca de Plantejar preguntes investigables i Dissenyar un experiment. També ho faria a l'hora de Recollir les dades, fent reflexionar a l'alumnat sobre allò que és important d'observar (On he posat els claus? Què esperava que passés? Per què? Què ha passat?...). Arribats a aquest punt, l'exercici es podria acabar aquí, demanant a l'alumnat que expliqués què s'havia fet $i$ extraient conclusions al mateix nivell que les que s'esperen en l'activitat més tradicional (Què he de fer per a que es rovelli un clau?), però estaríem de nou en explicacions locals, no en la construcció de models conceptuals rellevants. La clau en aquest punt és que l'activitat permeti anar una mica més enllà, permeti a l'alumnat construir explicacions en harmonia amb els grans conceptes científics, desenvolupar models que permetin donar explicacions sobre el fenomen concret observat, però també fer prediccions i explicar altres situacions. En aquest sentit, les qüestions que es plantegen en aquesta activitat tenen aquest objectiu: Quins canvis es poden observar? (canvi químic com a canvi de propietats, augment de pes com a combinació de "reactius",...). Aquestes explicacions permetran a l'alumnat donar explicacions molt més riques sobre el fenomen concret observat, servint la darrera pregunta com a aplicació del model construït a través de la indagació.

Què ha de passar per a que un clau de ferro estigui rovellat?

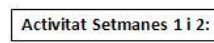

Disposeu de tres setmanes per a aconseguir
rovellar al maxim un clau de ferro i aconseguir que un altre clau de ferro no es rovelli gens

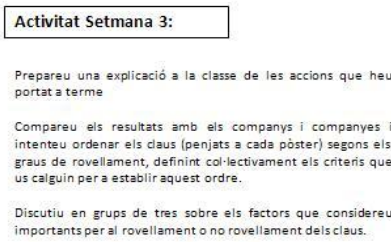

Discutrants ger al rovellament o no rovellament dels claus.

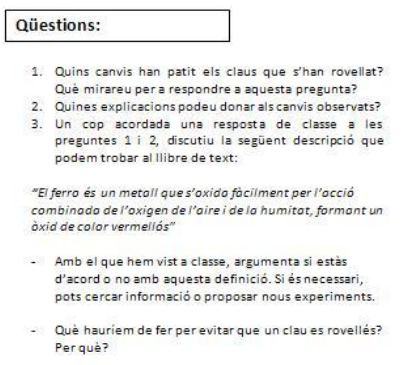

Figura 8. Treball pràctic "indagatiu" 
La Taula 2 compara ambdues activitats en base al marc proposat en aquest article.

\begin{tabular}{|l|l|l|}
\hline $\begin{array}{l}\text { Plantejament de preguntes } \\
\text { investigables rellevants per } \\
\text { construir, revisar i/o aplicar } \\
\text { el model }\end{array}$ & $\begin{array}{l}\text { No existeix una pregunta que guï̈ } \\
\text { l'activitat i les tasques que ha de por- } \\
\text { tar a terme l'alumnat. De fet, la res- } \\
\text { posta a la pregunta inicial ja es troba } \\
\text { a la "introducció teòrica". }\end{array}$ & $\begin{array}{l}\text { Totes les tasques que ha de portar a } \\
\text { terme l'alumnat vénen guiades per la } \\
\text { pregunta inicial, què és investigable i } \\
\text { que conecta amb el model/teoria que } \\
\text { es vol treballar.. }\end{array}$ \\
\hline $\begin{array}{l}\text { Disseny de l'experiment i re- } \\
\text { collida de dades }\end{array}$ & $\begin{array}{l}\text { L'experiment ja ve donat (materials, } \\
\text { mesures, ...) }\end{array}$ & $\begin{array}{l}\text { Dissenyat per l'alumnat (amb ajuda } \\
\text { del professorat) }\end{array}$ \\
\hline Plantejament explicacions & $\begin{array}{l}\text { Les explicacions que dóna l'alumnat } \\
\text { són molt locals }\end{array}$ & $\begin{array}{l}\text { L'alumnat prova de construir un mo- } \\
\text { del que li permeti donar resposta a } \\
\text { les preguntes plantejades }\end{array}$ \\
\hline $\begin{array}{l}\text { Comprovació / Avaluació de } \\
\text { les explicacions }\end{array}$ & $\begin{array}{l}\text { No és necessària perquè l'explicació } \\
\text { ja ve donada }\end{array}$ & $\begin{array}{l}\text { Es contrasta amb els resultats d'altres } \\
\text { companys i companyes }\end{array}$ \\
\hline Connexió amb la teoria & $\begin{array}{l}\text { La "teoria" que es vol introduir ja ve } \\
\text { donada des del principi, i és mera- } \\
\text { ment descriptiva. l'experiment ser- } \\
\text { veix només per visualitzar-la } \\
\text { /confirmar-la }\end{array}$ & $\begin{array}{l}\text { Es busca construir un model central } \\
\text { de la ciència (canvi químic), que per- } \\
\text { met a més ésser aplicat a un cas } \\
\text { concret (oxidació ferro) }\end{array}$ \\
\hline Comunicació & $\begin{array}{l}\text { El resultat final és local i no deixa de } \\
\text { ser una confirmació de la teoria intro- } \\
\text { duïda inicialment }\end{array}$ & $\begin{array}{l}\text { Es busca que l'alumnat expliciti les } \\
\text { explicacions i les connecti amb una } \\
\text { aplicació concreta }\end{array}$ \\
\hline
\end{tabular}

Taula 2. Comparació de les dues activitats de treball pràctic

\section{REFLEXIONS FINALS}

En el present article s'ha intentat recollir les principals reflexions sobre l'ensenyament de les ciències basat en la indagació (ECBI). Alhora, i per tal d'aclarir certes confusions que aquestes reflexions acostumen a apuntar, s'ha proposat un marc inspirat en la indagació basada en la modelització. Aquest marc pot servir com a guia o referència a l'hora de plantejar un treball pràctic amb enfocament indagatiu, posant molt d'èmfasi en la capacitat d'aquest treball en ajudar a l'alumnat a construir models conceptuals rellevants de la ciència i en oferir una visió correcta de l'activitat científica.

Prenent aquest marc com a base, es podrien plantejar recerques en didàctica de les ciències per tal d'avaluar quines característiques d'aquest marc es poden trobar entre les visions del professorat de ciències. L'equip de recerca que signa aquest article ha aplicat ja aquest marc en una petita recerca feta entre professorat de primària $i$ de secundària (8 mestres i professors i professores en total). Malgrat que aquest no és l'objectiu de l'actual article, creiem interessant destacar certs resultats d'aquesta recerca.

Aplicant el marc que s'ha proposat per al treball pràctic hem trobat que la majoria de professorat analitzat, tant de primària com de secundària, pre- senta unes visions sobre el treball pràctic que, si bé no contemplen totes les dimensions que s'encabirien en un cicle de treball pràctic indagatiu tal i com l'hem definit en aquesta article, permetrien un acostament al mateix si se n'aprofitessin les potencialitats. Tenir en compte les barreres i facilitadors identificats pel professorat (algunes intrínseques i d'altres extrínseques) podria ajudar a fer evolucionar aquestes visions cap a enfocaments més propers al marc presentat en aquest article. Aquest resultats podrien permetre plantejar mecanismes (formació del professorat, replantejament dels plantejaments de les aules de ciències a nivell de centre, etc...) que fessin possible l'entrada definitiva d'un enfocament indagatiu, en concret per al treball pràctica, a l'aula de ciències.

\section{AGRAIIMENTS}

El treball aquí presentat està finançat pel MICINN, com a part del projecte d'I+D COMPEC: "La competència científica en el professorat de ciències de secundària: anàlisi de dificultats, propostes de formació i elaboració de materials didàctics com "bones pràctiques" en l'àmbit", amb referència EDU2009-08.885 


\section{BIBLIOGRAFIA}

ABDULKADIR DEMIR, \& ABELL, S. K. (2010). Views of Inquiry: Mismatches Between Views of Science Education Faculty and Students of an Alternative Certification Program. Journal of Research in Science Teaching, 47(6), 716-741.

ANDERSON, R. D. (2002). Reforming Science Teaching: What Research says about Inquiry. Journal of Science Teacher Education, 13(1), 112.

BARROW, L. H. (2006). A biref history of inguiry: from Dewey to Standards. Journal of Science Teacher Education 17, 265-278.

BYBEE, R. W. (2006). Scientific Inquiry and Science Teaching. In L. B. Flick \& N. G. Lederman (Eds.), Scientific Inquiry and Nature of Science. Implications for Teaching, Learning and Teacher Education. (pp. 1-12). Dordrecht, The Netherlands: Springer.

DEMIR, A., \& ABELL, S. K. (2010). Views of Inquiry: Mismatches Between Views of Science Education Faculty and Students of an Alternative Certification Program. Journal of Research in Science Teaching, 47(6), 716-741.

LÉNA, P. (2009a). Towards an European strategy in elementary science education. In G. Santoro (ed.), "New Trends in Science and Technology Education" Conference, Abstract booklet, Università di Modena e Reggio Emilia, p. 71.

MILLAR, R. (2009b). Does practical work really work? A study of the effectiveness of practical work as teaching and learning method in school science. International Journal of Science Education, 30(14), 1945-1969.

MINNER, D. D., LEVY, A. J., \& CENTURY, J. (2010). Inquiry-Based Science Instruction-
What Is It and Does It Matter? Results from a Research Synthesis Years 1984 to 2002. Journal of Research in Science Teaching, 47(4), 474-496.

NRC. (1996). The National Science Education Standars. Washington D.C.: National Academy Press.

OSBORNE, J.. DILLON, J. (2008). Science Education in Europe: Critical Reflexions. Nuffield Foundation:

http://www.nuffieldfoundation.org/sites/default/fil es/Sci_Ed_in_Europe_Report_Final.pdf

ROCARD, Y. (2007), Science Education Now, Report EU22-845, European Commission, Brussels:

http://ec.europa.eu/research/science-

society/document_library/pdf_06/report-rocardon-science-education_en.pdf

SCHWARZ, C. V., \& GWEKWERERE, Y. N. (2007). Using a Guided Inquiry and Modeling Instructional Framewok (EIMA) to Support Preservice K-8 Science Teaching. Science Education, 91(1), 158-186.

TIBERGHIEN, A. (2000). Designing teaching situations in the secondary schoo. In L. J. Millar $\mathrm{R}$, Osborne J (Ed.), Improving science education: The contribution of research, (pp. 27-47). Buckingham: Buckingham.

VIENNOT, L. (2011). Els molts reptes d'un ensenyament de les Ciències basat en la indagació: ens aportaran múltiples beneficis en l'aprenentatge? Ciències, 18, 22-36.

WINDSCHITL, M., THOMPSON, J., \& BRAATEN, M. (2008). Beyond the Scientific Method: ModelBased Inquiry as a New Paradigm of Preference for School Science Investigations. Science Education, 92(5), 941-967. 